\title{
Olga Sanchez Finds Humanity in Latinidad
}

\section{Timothy Krause}

Raised in a traditional Colombian family on New York City's Staten Island, actor and director Olga Sanchez understands first-hand the challenges and rewards of being a bi-cultural theatre artist. Her undergraduate education and early career were shaped by work from the likes of William Shakespeare, Anton Chekhov and Tennessee Williams, but her subsequent experiences in the Pacific Northwest pulled her closer to the worlds of playwrights such as Federico García Lorca, Luis Valdez and Nilo Cruz. Now, as an artistic director of Miracle Theatre Group in Portland, Oregon, Sanchez draws on her bi-cultural heritage to create collaborative works that exemplify the human experience through a culturally informed lens of latinidad.

\section{What was your first experience in Latino theatre?}

For a long time, whenever I participated in ethnically identified arts, it was never the main focus of my work. On the East Coast, where I grew up and began my career, I was more likely to be directing plays like The Taming of the Shrew or Cyrano de Bergerac. I really had only one brush with a Hispanic writer when I worked on a scene in college from La casa de Bernarda Alba by Federico García Lorca. It was a surprisingly powerful experience. My director asked me to do the scene once in English and once in Spanish. When I did the scene in Spanish, I burst into tears. At the time, I had no idea of the power or the importance of this kind of work, only that I had a visceral connection to it. It was only after moving to the Pacific Northwest, taking myself to a very different place, that my work changed, my identity was broadened, and I found a new sense of purpose through culturally specific arts.

What was different about working in the Pacific Northwest?

In New York City, I was part of a very diverse community. No one really stood out because everyone was different. I didn't sense an 'us ver- 
sus them'. But in Seattle, I was immediately identified as Latina both by the public at large as well as the Latino community. Although I was cast in plays by Steven Dietz and Y York that were ethnically neutral, suddenly I was also cast in works by José Cruz Gonzalez, Milcha Sanchez Scott and Carlos Murillo - works that were decidedly Latino. It was a strange thing to be suddenly ethnic. I always thought that I was 'American'. But in the Northwest, I was exotic - and even more rare, a trained bilingual theatre artist, as well. [Sanchez has trained with Peter Brook, André Serban, Mary Overlie and Augusto Boal, among other master theatre artists.]

What happened in Seattle that focused your attention on culturally specific arts?

I was working on a show with a writers group called Los Norteños, an evening called Una noche de liberación. It was a slate of one-act plays by writers who were not really playwrights but who decided they wanted to try writing plays. So I paired them up with dramaturges, directors and professional actors. Near the opening night, one of the writers cornered me in great frustration about some technical thing that we were still working on. I understood his concern; he was a novelist - a lawyer by trade who had grown up in a migrant worker camp - who was having his first play produced. But most important was what he said to me, which I'll never forget: "They're watching us. Everybody outside the Latino community is watching us to see whether we are going to fail. They can't wait for us to make a mistake or to be less than perfect." His passion — his panic — was so palpable. It struck me as a call to responsibility: I became aware of how serious work like this is because it represents who we are, it speaks for us and, as our mouthpiece, can be our harshest critic and our most valued champion.

\section{How did this affect you and your career?}

I don't think I knew how big a question it was for me personally until I participated in a gathering of representatives from the Campus Diversity Cultural Resource Initiative held in Memphis, Tennessee. One exercise in particular brought our group into a circle and asked everyone to identify a moment when they experienced discrimination based on ethnicity. So people went around the room and talked about horrific situations. When they got to me, I couldn't really recall any concrete example of discrimination. Everybody nodded and looked at me like I was crazy but continued around the circle. Then, about three people down the line, I suddenly burst into tears. I realized 
that I had discriminated against myself, for years. I had experienced bouts of extreme self-doubt because I didn't see how I was ever going to succeed; there weren't any examples of successful Latinos, I thought it must be inherent to my culture. Even though every single Hispanic I ever met was incredibly hard-working, for some reason I thought we, as a group, must not work hard enough, or else we'd be more successful. This drew me to work that combats negative biases. I confronted my own internalized oppression and committed myself all the more to community work, especially to help provide positive cultural experiences for young people who are the most impressionable. The way I can do that is through theatre and through art, because that is my craft, my skill, my training. In essence, I am an arts activist.

After co-founding and leading both Seattle Teatro Latino and La Casa de Artes, you embarked on a master's degree program in human development from Pacific Oaks College NW. How did this tie in with your arts activism?

I studied my own preconceived notions, learned why ethnically identified work is crucial, and learned how to work respectfully within a community, to be an effective agent for social change without being militant. My thesis was on the development of ethnic identity in people who participate in creative collaborative events, how working with those who have a strong cultural identity helps those of us who are bi-cultural - who feel we fit neither here nor there - to gain a sense of belonging by acquiring cultural competence and acceptance. Basically I learned the skills with which to carry out my 'mission' to create environments where no one would feel like a second-class citizen because of their other-ness. It provided context for my art, and a sense of purpose.

How does this convergence of your professional and personal journeys inform your work as one of the artistic directors of Miracle Theatre?

Working at Miracle is a blessing because it nurtures my creativity and reinforces my responsibility. It's allowed me to investigate cultural tradition as a launching pad for aesthetic choices onstage. I naturally gravitate to poetic text and find movement a tremendous vehicle for heightened language, making intentional choices based on the specific cultural landscape of the play. For example, the first play I selected as artistic director was Elaine Romero's Barrio Hollywood, where I incorporated equally the movement and gestures of folkloric dancing, boxing and prayer in order to add visceral impact to the text. The play was about fighting to stay alive, and having the grace to fall in 
love - with movement, these themes became physical events, not just ideas. For Quiara Alegría Hudes' The Adventures of Barrio Grrrl!, I worked with an Afro-Cuban choreographer to integrate traditional Orisha dances that helped lift the comic book story to the level of a spiritual quest. And in Nilo Cruz's Lorca in a Green Dress [for which Sanchez won a regional Drammy award for outstanding direction], we instilled the movement, gesture and rhythms of flamenco in each of the characters, a cultural connection that immediately rooted the performance of this surreal play in the duende of 1930s Andalucía.

\section{What inspires you as an artist?}

In general, I'm inspired by the complexity of the human experience, by the choices we make in life and how we are influenced by what is real and what is perception. I am fascinated by what shapes us, by questions of fate, influences of society, and the power of grace. But I am also frustrated at times, by how we make meaning. Our popular media teaches us that legitimacy requires accessibility, that if something makes sense to many, it must be right. Of course that's valuable - it supports democracy and teamwork, for example - but it also limits our tremendous capacity for nuance, diversity and for understanding each other more deeply.

Much of your work at Miracle is bilingual but in different ways. Spanishlanguage productions are presented with super-titles projected in English. In the company's annual Day of the Dead celebration, however, a scene presented in English may be followed by a song in Spanish, both of which stand alone without translation. A third method, utilized primarily by the theatre's national touring troupe, interweaves English and Spanish into the natural flow of dialogue so that a monolingual speaker's experience is expanded by context. How does this affect the connection with the audience?

The bilingual work that we do is possibly the most successful, not just because it increases access to all of our work, but because it challenges our audiences. Many of our audiences are learning Spanish or English, and this work allows them the opportunity to leap into the unknown. Bilingual theatre opens the heart and the mind, challenging audiences to grasp meaning beyond the literal. I love this work because it proves you don't have to understand it all to understand.

Can you give an example?

In 2010, Miracle will produce a bilingual work of yet another type when we produce How the Garcia Girls Lost their Accents, a play by Karen 
Zacarías based on the best-selling novel by Julia Alvarez. The story follows four sisters living in New York City backward in time to when they were children in the Dominican Republic. Although the women speak fluent English at the beginning, by the end of the play they are conversing exclusively in Spanish. This, I hope, will take audiences on a journey of compassion where they can feel what it must have been like for these girls to encounter this language, not to mention a culture that was simultaneously familiar and foreign. The story is entertaining and fun, but also a visceral experience that changes the soul, the spirit of the audience. Many of our audience members won't know what the characters are saying at the end of the play, but that sensation of disorientation can be worthwhile when it generates empathy.

Why wouldn't audiences understand what is said at the end of the play?

The final scene, in which we've traveled back in time with the girls to when they were growing up in the Dominican Republic, is in Spanish. No translation, no subtitles. Granted, it's not complicated dialogue and a great deal of context has been established by then, but here in Portland, monolingual English speakers still constitute a majority of our audiences and they will have a different, though no less rich, experience — one that will undoubtedly strengthen their relationship to the characters.

In Portland, Mexicans constitute the predominant Latino culture, but not all of the work presented at Miracle is Mexican. Why is that?

One of the foresights of Miracle's founders José González and Dañel Malán was to create a pan-Latino theatre. We purposefully seek out a variety of work from across Spain, Latin America and the U.S. with an intention to examine the diversity of cultural expression, stories and histories, in order to acknowledge that there is a bigger picture out there. The Latino experience is diverse, and yet there's also something that's unifying. That's a fascinating investigation: "What is the thing that ties latinidad together?" For too long, Latinos in the U.S. have been a bit divisive, using culture as a wall instead of a bridge.

\section{Where does that bridge lead in terms of what goes onstage?}

Unlike at other ethnically identified theatres situated in communities with large Latino populations, I often work with casts that bring Latinos from around the world to work with each other and with non-Latinos That's collaboration that cannot help but influence and inform the work onstage. 
We have a unique opportunity in Portland, because of the diversity of people who are making the Northwest their home, to create new forms based on the exchange of cultures, an exchange that is born of mutual respect and the search for truth that is at the core of art. It is a process of distillation, intentionally seeking truth in each act of theatre. I get to work with people who approach the work with fresh, curious eyes, enabling us to look beyond the surface to what really speaks to the universal human experience and builds respect and understanding.

But does a smaller pool of Latino artists also limit your choice of plays?

Yes, every once in a while a play comes along that I would love to be able to share with our audiences, but because of our location, it's not feasible. For example, a few new plays have come along recently that explore several fascinating situations: machinations of urban politics, toxic romances found in rave nightlife, employment of undocumented immigrants, to name a few. These are brilliant plays that demand experienced, well-trained actors who can meet the challenges of the work, and because of the nature of the stories, require the verisimilitude afforded by casting ethnically-appropriate actors. I have in the past cast inexperienced actors, and I do so because I believe in nurturing new talent, but in some cases the play is not realized to its fullest potential. Without a budget to bring in actors from Los Angeles or New York, I opt to select other great plays that I know we have the resources to deliver well. And those other scripts, they stay on my shelf for the future, when the actors we need arrive to town! I have faith that they will. Our vision is for Miracle to be a mecca, drawing not only audiences and patrons, but artists from all over the world.

\section{What would that look like?}

In 2008, for example, Miracle created an original production called Oyá: Call the Storm, for which we assembled a company of artists that included a Cuban choreographer, Peruvian dancer, Mexican-American director and two Puerto Rican actors, one of whom was trained in contemporary American acrobatics. Together, they generated a dance theatre performance that blended all of these aesthetics, from salsa dancing to Cuban Orisha songs. It was a transformation of forms, a challenge that keeps our artistic juices flowing. I'm excited about that artistic dialogue that asks, "How do we honor what makes us unique, while also recognizing the humanity and beauty of others?" 
In theatre, what do you see as the difference between your Colombian background and, say, the work of a Chicano or Puerto Rican artist?

I can't speak for the individual Chicano or Puerto Rican artist but, speaking generally, our experiences and priorities have been different. The Chicano is historically battling for equality in a land they once owned. The Puerto Rican has historically longed for independence for their island. Both of those cultures have brought significant influences upon the mainstream culture in many ways, and I've encountered far more plays by Chicano and Puerto Rican playwrights that directly address their cultural experience in the U.S. Colombians have less of a cultural presence and unfortunately the country itself has had some bad press, with its seemingly never-ending civil war and illegal drug industry. I'm thrilled that I'll be directing El Quijote by Teatro la Candelaria founder Santiago García in 2010; I also had the opportunity to appear in the world premiere of Never Whistle While You're Pissing by Carlos Murrillo, a Colombian American. My journey as Latino-identified artist has been to learn about other Latino cultures and histories. When I performed in a workshop of José Cruz González' Harvest Moon, I had no knowledge of the farm-workers' struggle in California; I grew up in New York City and thought machines harvested crops. Beyond history, I had to learn a new vocabulary, a California Chicano Spanish. As I approach Santiago García's play, knowing he wrote it with his war-afflicted audience in mind, I am searching for the connections between Colombia's state of affairs and our own.

\section{What's next?}

Personally, I'm seeking balance between art and life. Professionally, my dream is a school, where young artists are trained by Latin American master teachers, and we create art that is infused with the vibrancy, poetry, spirituality and muscularity of latinidad. 
